\title{
Managing knowledge as quantity surveyors: An exploratory case study in Sri Lanka
}

\author{
S.Senaratne, S Sabesan
}

\begin{abstract}
Being one of the key professionals in the construction industry who is the expert in construction cost management, quantity surveyor has a necessity to manage its knowledge to continuously learn and improve. Quantity surveyor has the responsibility to address cost, financial and contractual issues of the construction process, which is highly influenced by environmental parameters, which are very sensitive to changes and unique for every project. These key drivers have made them to relate and narrate new conditions with existing knowledge and past experience. Quantity surveyors can accomplish this expertise by learning from the past and sharing knowledge within the profession. Thus, the study which is reported in this paper is aimed at exploring issues related to quantity surveyors in Sri Lanka when managing their knowledge in order to learn and improve as professionals. Case studies were used to investigate this research problem. The case studies specifically explored key challenges faced by Quantity Surveyors and their knowledge transfer and sharing processes. These were compiled into a framework to represent the managing knowledge process of Sri Lankan Quantity Surveyors. The findings further revealed even though the Sri Lankan Quantity Surveyors are performing well in their duties with their current level of knowledge, due to very tight work schedules and comparatively low recognition to other construction professionals, there are less opportunities for them to acquire new knowledge and develop tacit knowledge base. Thus, the findings offers implications to construction industry and other professionals, too, as to improve wider knowledge dissemination mechanisms within the industry and more specific implications include for managerial level quantity surveyors to open up discussions with government departments and make them aware of quantity surveying and make it recognised in the country. Further, junior quantity surveyors should not just consider profit maximisation but also continuous professional development by acquiring and utilising new knowledge in their day-to-day work, so that the profession will develop as a whole.
\end{abstract}

\section{Background}

The construction sector is a vital part of any economy because of its size and the potential role it can play in the development efforts of the economy (Nisa et al., 2006). Construction is often used as an indicator of socio-economic development of a nation and, therefore, it is indispensable in the process of socio-economic development. Its contribution to the national economy is well represented through the construction value addition, investment, employment, trade balance and sectoral linkages. But, unlike other sectors, construction sector delivers its products to unique and, sometimes, exceptional prerequisites of topographical and geographical conditions of the exterior environment, where change is a norm. Such change drivers have always made the professionals in the construction industry to relate and narrate new conditions with existing knowledge and past experience. Quantity surveyors, as well as other key players in the construction team, meet with new conditions which demand them to manage their knowledge effectively.
According to Willis and Ashworth (1987, p.2), the Quantity Surveyor (QS) is the one who "ensures that the resources of the construction industry are utilised to the best advantages of society by providing, inter alia, the financial management for projects and cost consultancy services to the client and designer during the whole construction process." A similar definition is offered by Nisa et al. (2006, p.43); "...the quantity surveyors also referred to as the construction cost consultants, building economists, construction economists or cost engineers are the professional experts in construction cost management."

As emphasised, being one of the key professional experts in the construction sector, quantity surveyors have the utmost responsibility to address the key cost, financial and contractual issues of the construction process, which is always highly influenced by the environmental parameters, which are very sensitive to changes and are unique for every project. These 
key drivers have always made the professionals in the construction industry to relate and narrate new conditions with existing knowledge and past experience. Egbu et al., (2003b, p.30) state that "... construction is experience-oriented. Experience gained through site work is necessary." As Nonaka (1991, p96) affirms "in an economy where the only certainty is uncertainty, the one sure source of lasting competitive advantage is knowledge. When markets shift, technologies proliferate, competitors multiply and products become obsolete almost overnight, successful companies are that constantly create new knowledge, disseminate it widely throughout the organisation, and quickly embody it in new technologies and products." Hence, quantity surveyors can accomplish this expertise by learning from the past and sharing Knowledge in quantity surveying field. In this era, the concept of 'Knowledge Management' (KM) is widely researched and recognised. Thus, knowledge management is not entirely new to the construction industry (Carrilo, 2004). But, there is a dearth of research studies in relation to the Quantity Surveying profession. Thus, the study which is reported in this paper was aimed at exploring issues related to quantity surveyors in Sri Lanka when managing their knowledge in order to learn and improve as professionals. Next section described the research method used.

\section{Research Method}

Since the study reported in this paper is of exploratory nature and requires an in-depth understanding of knowledge about the practices and procedures in the organisational context as well as industry wide, it requires approaching the prominent key professional quantity surveyors practicing in the construction industry. Hence, gaining in-depth information and accessing to the key professionals remains the fundamental requirement for the study. It has been argued through out the study that an implementation process must be studied in its natural setting in order to capture the complexity and the contextual features that affect the process.

It has been argued that, when a phenomenon of interest requires detailed and in-depth information, a qualitative research approach (Yin, 1994) best suits that. As mentioned above, this research requires studying real life context in depth, through a detailed investigation of data collected over a period of time, of phenomena, within their context, without isolating from its context. Hence, among the numerous approaches available in the qualitative approach, case study research approach has been adopted. According to Eisenhardt (1989), the case study is a research strategy which focuses on understanding the dynamics present within single settings and can employ an embedded design, that is, multiple levels of analysis within a single study. Thus, this approach makes possible to access professionals and staff of all levels, who could explain their views on the key challenges, knowledge transfer and knowledge creation processes which subsequently would lead to better understand and evaluate current context and scenario of the quantity surveyors in Sri Lankan construction industry.

As the study focuses on the concept of knowledge management with regard to quantity surveyors, the quantity surveying professionals practicing in the Sri Lankan construction industry has been the key focus. Nine case studies were done and the primary data collection was through semi-structured interviews that spanned 1-2 hours. Interviewees at different top levels of the organisation were targeted. Basically this was to ensure that findings are rich in nature and to better understand the status quo though the dominant professionals in the industry. Most of the data were collected from the key professionals who are at the top managerial levels such as chairman, directors, managers, chief quantity surveyor and senior quantity surveyor. Data was analysed using code-based content analysis and mapped using cognitive mapping.

\section{Need for managing knowledge as quantity surveyors}

By the mid of the 20th century quantity surveying had evolved to a recognised profession in the construction industry with the traditional role of keeping accounts and controlling of construction costs for both the client and the builder (Ashworth and Hogg, 2002). This clearly emphasizes that the prime role of the quantity surveyor, pivots around the aspect of cost control of projects from inception to completion, which requires a detailed knowledge of contractor's prices, experience of the construction process and an ability to foresee the likely effect of economic trends (Willis and Trench, 1999).

Although, the prime and essentially, the core role of quantity surveyor rotates around the concept of cost control, clients in the modern construction industry increasingly look forward to the business advantages in enlisting property to their portfolios. However, the constraints generated from scarce resources necessitate them to seek more value for money in their investments (Perera, 2006). The new approaches in construction culture, procurement strategies, changing markets, delivering added value and supply chain management, partnering, private finance initiatives have directed the construction industry towards a new route of evolvement. The importance of this is further emphasised due to the declining role of manufacturing and increasing growth in the service sector of the economy (Cartlidge, 2002). These effects and expectations on and from the construction sector have always been directed towards the quantity surveyors, since they have the capacity and the capability to diverse into new arrays such as; value management, risk management, project management, whole life 
costing and similar other newer techniques to add value to the construction process (Ashworth and Hogg, 2002).

In order to subsist and grow in the future, quantity surveying profession has the utmost necessity to respond to the accelerating social, technological, economical and environmental changes quickly as well as productively (RICS, 1992). Future quantity surveyors are required to have a thorough knowledge and understanding of the client's operating environment, their strategic dilemmas and aspirations, their values and the organisational culture the client is attempting to foster (Pathirage and Amaratunga, 2006). Further, managing knowledge more effectively offers construction organisations a possible mechanism for improving their performance in times of greater competition (Carrillo, 2004).

The processes involved in each construction project exhibits its uniqueness and difference in terms of goals and contexts. Engineers, architects and other professionals within the construction industry are not in a position to 'cut and paste' best practice (Kamara et al., 2003) from the past, due to the unique and the complex nature of the construction projects. This is where the construction industry deviates from other industries of the economy and, is a specific challenge for the professionals of the construction industry, in order to formulate a system, as to how the knowledge of such multiplicity could be well managed. Hence, there is an utmost necessity, for the professionals of the construction industry, to adopt all possible varieties of knowledge, with regard to the existing and probable modern diversities. Since, the quantity surveyor too is one of the key professionals, in order to be successful and competitive, the quantity surveyor, needs to have very specific knowledge concerning the existing arrays of services provided and, the potential probable career diversifications (Nisa et al., 2006). This type of competent knowledge typically exists as folklore and is informally maintained within the brains of the experienced personnel (Nonaka and Takeuchi 1995; Empson, 2001; Egbu et al., 2003a; Robinson et al., 2005; Zou, 2004; Carrillo, 2004). This knowledge is disseminated to inexperienced junior quantity surveyors from experienced, through various tools of knowledge transfer such as discussions, training, correspondence, tutoring and observation. At the same time, it must be made sure that this knowledge is also passed into the knowledge base of the organisation and made available to everyone who needs it. When knowledge within the organisation is shared, it becomes cumulative. It becomes embedded within the organisation's processes, products, and services (Demarest, 1997). These concepts of knowledge transfer and knowledge sharing are all sub processes of the whole knowledge management processes.
Implementing knowledge management in any organisation is a high challenge because of the time and effort that is required before it starts to offer return on the investment. Among these, organisation culture is one of the most crucial factors (Davenport et al., 1997; Robinson et al., 2005) as people within the organisations show reluctance to change their ways of working. Thus, a cultural change is required to facilitate full effect of knowledge management (Egbu et al., 2004). In addition, this cultural behaviour has the effect that a long-term investment such as knowledge management and learning for the next project are not prioritized. Instead, project managers are interested in finishing the current project on time. As long as management does not allow the culture to change and does not allow employees to invest in managing their knowledge, knowledge management is not likely to happen. Other barriers include demonstrating and communicating the benefits and resistance to knowledge sharing, initiative overload, poor IT infrastructure, lack of top management support (Robinson et al., 2004). These facts simply emphasise needs and necessities of knowledge management in quantity surveying and the challenge for knowledge management in quantity surveying but, they are not defined or examined in detail.

To this end, general knowledge management literature offers significant insights to understand how a professional could manage knowledge through better knowledge transfer and creation processes. Next section summarise the key findings from this literature review which relating them to QS profession.

\section{Knowledge transfer and knowledge creation processes}

According to Nonaka (1994), in an organisation, at the fundamental level, knowledge is created by individuals. The organisation cannot create knowledge without individuals. The organisation supports creation of knowledge at the individual level. Such created organisational knowledge needs to be shared, crystallised, justified and networked in order to be amplified organisationally, to be productive. Hence, the prime movers in the process of organisational knowledge creation are the individual members of the organisation. Among the numerous sources of knowledge creation, the accumulation of tacit portion of the whole knowledge is the most challenging and tough task, which primarily depends on experience. This clearly mitigates that the quality of the accumulated tacit knowledge depends on two key factors, which highly influence such knowledge creation, namely; 'variety of an individual's experience' and 'knowledge of experience.' Hence, appropriate response from the profession to enhance its knowledge domain is of significance. 
According to Pathirage and Amarathunga (2006), since the needs and expectations of the clients are ever changing facts, in order to compete and to excel in the profession, quantity surveyors have to acquire and operate wide range of diverse skills outside the normal traditional QS. As Brandon (1990) suggested, an appropriate response from the profession should require enhancing its knowledge domain, so as to move quickly into new areas of services as opportunities arise and move away from methods when technology and competition make them redundant. In addition, knowledge is created when getting involved in diverse construction projects.

Although the prime movers in the process of organisational knowledge creation are the individual members of an organisation, "yet, these perspectives remain personal unless, they are articulated and amplified through social interaction" (Nonaka, 1994, p. 22). The importance this social interaction is further highlighted by Brown and Duguid (1991) though their 'communities of practice' concept.

The knowledge created through the interactive process among the team members need to transferred to other members to effective manage knowledge. Argote and Ingram (1999) define knowledge transfer as "the process through which one unit (e.g., group, department, or division) is affected by the experience of another" (p. 151). Szulanski (2000) viewed knowledge transfer as a process in which an organization recreates and maintains a complex, tacit set of routines in a new setting. Several authors have discussed on the factors that affect effective knowledge transfer. These could be group as individual, group and organisational level factors.

At individual level, factors such as absorptive capacity (Cohen and Levinthal, 1990), values and motivation can be considered. At group level, factors such as distance (Gailbraith 1990), language, cultural differences (Kane et al., 2005) and trust among individuals (Boiset, 1995; Goh, 2002) are key contributors that hinder knowledge transfer. At the organisation level, organisational structure, culture, union management relationships and incentives are most influential factors on knowledge transfer.

Literature on knowledge transfer also offers tools to effectively transfer knowledge while overcoming above knowledge transfer inhibitors. Non-IT tools include brainstorming, training, recruitment, knowledge gate keepers, inter company learning, face to face interaction, exit interview, community of practice whereas IT tools include intranets, extranets, knowledge bases and groupware (Egbu et al., 2003c).

The above discussed points in terms of knowledge creation and transfer will be explored in the case studies as discussed in the next section to understand the picture in Quantity Surveying profession.

\section{Case study findings}

\subsection{Key challenges}

Due to these dependency on other design professionals and design changes, a respondent mentioned time as a key challenge for quantity surveyors.

One respondent emphasised that knowledge transfer is a problem due to lack of experienced personnel in the local industry. The experienced quantity surveyors are moving abroad creating a vacuum in the local industry. However, quantity surveyors who operate in Sri Lanka are not given due recognition according to one respondent which in turn has created lack of opportunities to enhance their knowledge. Besides, findings revealed that lack of team work and conflict of interests are challenges faced by construction industry as a whole.

In overcoming these challenges one interviewee emphasised the importance of sharing knowledge and expertise; standardising work; creating interactive forums to disseminate the knowledge of experienced quantity surveyors; and, introduce short courses or training programmes. In doing so, several respondents mentioned that universities and professional bodies need to take a lead role. On the whole, the quantity surveyors need to move beyond their traditional role to create new methods of working by gaining new knowledge through interaction and internalisation.

\subsection{Knowledge creation}

In quantity surveying, similar to other fields, it has been accepted that the knowledge creation starts at the individual level. Key personnel who contribute to the overall knowledge creation of individuals as identified in case studies are, institutions; company superiors; and, other stake holders such as consultants, suppliers and manufacturers. Such created knowledge is enlarged by the environment such as; working methods and technical knowledge and individual characteristics such as personal abilities and interest to gain knowledge.

The findings revealed that quantity surveyors get less opportunity to gain diverse knowledge on overall functions of a quantity surveyor as they are generally expected to work on a specific monotonous routine task. The organisations expect them to be experts on a specific area, so that similar form of work can be always directed towards the specialist. In case of project diversities, most of the Sri Lankan quantity surveyors are engaged in building projects, because of less opportunity. One respondent echoed, "even if the opportunity arises only top level seniors are allowed to put hands on to it." Separated procurement system which is very popular in Sri Lanka is seen as another impediment for knowledge creation. But, some re- 
spondents pointed that there are some opportunities for knowledge creation when working for international consultants, working on package deal projects and virtual projects.

Due to the nature of quantity surveyor's job, doubleloop learning is difficult to crystallise to a reasonable level. According to a respondent, "best way of learning is by mistakes." Although in the general perspective the individuals learn through involving in the work, making mistakes, seeing the repercussions and learn from it, quantity surveyors cannot afford to do mistakes as their profession is more risky. The possible alternative is to first involve in dummy tasks where cost, time and quality are of not of high importance. In addition, learning from an experienced is another mode. One respondent explained this; "you do not have to work for that number of years to get knowledge of an experienced person. You can learn fast being with an experienced person."

According to respondents, informal discussions are the main modes of knowledge sharing. Some held the view that although it is not ethical to hoard knowledge without sharing, in certain instances it has to be so, in order to secure the competence. On the other hand, quantity surveyors do not get a chance to share knowledge as they are generally "running against time."

For the industry as a whole to benefit, the knowledge created and shared among members and departments of a specific organisation has to be widely disseminated in the industry. In the opinion of one respondent, "very little interaction between organizations, probably less than $5 \%$ of the knowledge gets transferred." As far as the quantity surveyors are concerned, their opportunities of interactions are very little. Hence, at the industry level it does not get disseminated widely.

\subsection{Knowledge transfer}

In the view of most of the respondents, it is quite difficult to tackle the situation if a good quantity surveyor is leaving the firm, but if the company has adopted good knowledge transfer mechanisms this problem cold be minimised.

The key factors that hinder knowledge transfer in the respondents' view are organisational structure, trust, lack of knowledgeable personnel, communication, workload, working environment, attitude and conflict of interest. Among these trust was viewed as the most significant factor by all respondents. Ability to compete, competency and the reliability are related parameters of trust. Among other professionals involved in the construction sector, the quantity surveyor is the one who handles finance and therefore he needs to be trustworthy, especially with regard to activities such as evaluation of tenders, checking whether the rates quoted by contractor are reasonable, certifying the payments and valuing variation.

The findings revealed widely used knowledge transfer tools in Sri Lankan construction industry such as workshops, brainstorming sessions, discussions, training, seminars, memos, correspondence, recruitment, tutoring and people transfer. Recruitment is a significant knowledge transfer mechanism in terms of Quantity Surveyors as experienced QS come back to Sri Lanka after working abroad for several years.

With regard to technologies, internet is used in most quantity surveying firms, but databases are limited to major organisations. The web database operated by the quantity Surveyors society in Sri Lanka facilitates knowledge transfer process to some extent.

The above key findings in relation to managing knowledge as quantity surveyors in Sri Lanka are summarised into a framework (see Figure 1).

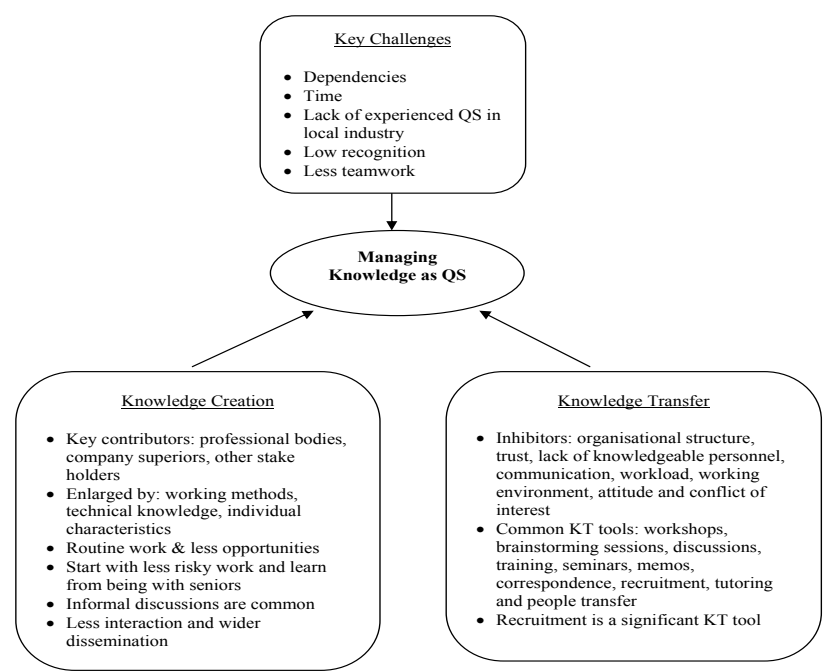

Figure 1: Framework on Managing Knowledge as Quantity Surveyors

\section{Conclusions}

Quantity surveyor, being the financial manager of the construction industry and has the ability to diverse his services is the one who has the capacity and capability to address most of these challenges which are directed to the industry. But, the case study findings of the Sri Lankan industry reveals inadequate independent services; unhealthy competition among consultants; documentation errors; all other professional's mistakes had to be covered by the quantity surveyor in terms of variations and claims; judgemental skills required in terms of time, cost and quality; and the unstable economic condition of the country. These factors urge the quantity surveyors to innovate along the way, through managing knowledge and expertise to survive and to be competitive in the dynamic industry. 
There are several practical implications for quantity surveyors practicing in the junior and managerial administrative level, as numerous new facts were explored. As identified in the case study findings, due to the higher turn over, higher international demand, lack of experienced personnel, which are unique features of the overall quantity surveying profession of the Sri Lankan industry, to cater the current demand and to always be with professional dignity, integrity and to always remain one of the key competent professionals, these implications have been thought of immense beneficial.

When the managerial level quantity surveyors are concerned, as they face a challenge of uncertainty and ambiguity of the junior level quantity surveyors, with regard to their existence in the company and, as the job itself is of the nature for another fresher to find it bit difficult to continue from the previously departed, a standard procedure has to be implemented. The standard procedure in the sense, senior level personnel has to be most of the time having an eye on the junior level and, all the approvals going through him. Also the managerial level should not overload the quantity surveyors and they should involve the junior level in most of the different functions, rather than assigning the routine operations. This will to certain extent make the job interesting and consequently reduce the turn over to a certain degree. Further, the storage should be more in the form of documentary visuals and films which would induce the junior level to have an eye on it. Internal workshops and training programs too have to be improved. Involving the junior level in brainstorming sessions and meetings will motivate the junior level in working more effectively. In addition, the managerial level quantity surveyors should open up discussions with government departments and make them aware of quantity surveying and make them recruit QSs, which subsequently would make the country recognise the QSs. Also they are expected to contribute to the institutional activities, by providing information with regard to those experienced who return from abroad on leave, so that at the industry level, some knowledge disseminating activities could be implemented. For the junior level, as the opportunities are very less with regard to project diversities, and the organisations, most of the time focus to reap the benefits and expect them to be experts on a specific area, it is upto the junior level to search for the knowledge and mount up their knowledge base.

While this is an exploratory study to identify issues in relation to managing knowledge as quantity surveyors further research is needed to further find out details on different knowledge management processes; in particular, on knowledge creation and transfer processes. Also, this research can be extended to study how quantity surveyors learn and develop within the construction industry.

\section{References}

ARGOTE, L. AND INGRAM, P., 2000. Knowledge transfer A Basis for Competitive Advantage in Firms. Organizational Behavior and $\mathrm{Hu}$ man Decision Processes, 82(1), 150-169.

ASHWORTH, A. AND WILLS, J., 1987, Practice and procedure for the quantity surveyor, 9th ed, Blackwell science Itd, Oxford.

BOISOT, M. H., 1995. Information Space: A Frame work for Learning in Organizations, Institu tions, and Culture, Routledge, London.

BRANDON, P., 1990, Quantity surveying techniques; new direction.London:Blackwell Science Ltd.

BROWN, J. S. AND DUGUID, P., 1991. Organisa tional Learning and Communities of Prac tice:Towardsa Unified View of Working, Learning and Organisation. Organisation Sci ence, 2 (1), $40-57$.

CARRILLO, P., 2004. Managing knowledge: lessons from the oil and gas sector. Construction Management and Economics, 22, $631-642$.

CARTLIDGE, D., 2002. New Aspects of Quantity Sur veying Practice.London: Butterworth Heine mann.

COHEN, W. M. AND LEVINTHAL, D. A., 1990. Ab sorptive capacity: a new perspective on learning and innovation. Administrative Sci ence Quarterly, 35, 128-52.

DEMAREST, M., 1997. Understanding knowledge management. Long Range Planning, 30 (3), 374-384.

DAVENPORT, T. AND PRUSAK, L., 1998. Work ing knowledge: how organizations manage what they know? Boston: Harvard Business School Press.

EGBU, C., QUINTAS, P., ANUMBA, C., KURUL, E.,HUTCHINSON, V. AND RUIKAR, K.., 2003a.Knowledge Production Resources \& Capabilities in the Construction Industry work package 1 - Final Report. Available at: http://www.knowledgemanagement.uk.net. [Date of access: March 15, 2006].

EGBU, C., QUINTAS, P., ANUMBA, C., KURUL, E.,HUTCHINSON, V. AND RUIKAR, K.., 2003b. A Systematic Analysis of Knowledge Practices in other sectors: lessons for construction. Available at: http:// www.knowl edgeman agement.uk.net. [Date of access: March 15, 2006]. 
EGBU, C., QUINTAS, P., ANUMBA, C., KURUL, E., HUTCHINSON, V. AND RUIKAR, K.., 2003c.Techniques and Technologies for Knowledge Management. Available at:http://www.knowledgemanagement.uk.net. [Date of access: March15, 2006].

EGBU, C., QUINTAS, P., ANUMBA, C., KURUL, E., HUTCHINSON, V. AND RUIKAR, K.., 2004. Knowledge Management for Sus tainable Construction Competitiveness. Avail able at: http://www.knowledgemanagement. uk.net. [Date of access: March 15, 2006].

EISENHARDT, K. 1989. Building Theories from Case Study Research. Journal of Manage ment Review, 14 (4), 532 - 549.

EMPSON, L., 2001. The Challenge of Managing Knowledge. In: T. DICKSON, ed., Mastering Strategy. Financial Times/Pitman Publishing.

GALBRAITH, C. S., 1990. Transferring core manu facturing technologies in high-technology firms. California Management Review, 32, 56-70.

GOH, S. C., 2002. Managing effective knowledge transfer: an integrative framework and some practice implications. Journal of Knowledge Management, 6(1), 23-30.

KAMARA, M. J., ANUMBA, J. C., CARRILLO, P. AND BOUCHLAGHEM, N., 2003. Conceptual frame work for live capture and re use of project knowledge. Construction informatics digital library, Available at: http://itc.scix.net/data/works/ att/w78-2003178. content.pdf.

[Date of access: March8, 2006].

KANE, A. A., ARGOTE L. AND LEVINE J., 2005. Knowledge transfer between groups via per sonnel rotation: Effects of social identity and knowledge quality.Organizational Behavior and Human Decision Processes,96(1),56-71

PATHIRAGE, C., AMARATUNGA, D., 2006, A vision for the quantity surveying education in the 21st century: united kingdom perspective, in the proceedings of the QS 2006 symposium: Customising the quantity surveyor to face challenges in year 2020, Galle Face Hotel, Colombo, Jan 2006

PERERA, S., 2006. Quantity Surveying: A Detailed Appraisal of the Profession and a Vision for the Future, In R. RAMEEZDEEN AND I. SENEVIRATNE, eds.Customising the QS to face Challenges in Year 2020, Colombo 26 January 2006. Colombo: University of Moratuwa.
NISA, Z., ROSHANI, P. AND THURAIRAJAH, N., 2006. Career Paths in Quantity Surveying, In R. RAMEEZDEEN AND I. SENEVIRAT $\mathrm{NE}$, eds. Customising the QS to face Chal lenges in Year 2020, Colombo 26 January 2006. Colombo: University of Moratuwa.

NONAKA, I.,1991.The knowledge creating company, Harvard Business Review, 69(6), 96-104.

NONAKA, I., 1994. A Dynamic Theory of Organiza tional Knowledge Creation. Organization Sci ence, 5 (1), $14-37$.

NONAKA, I. AND TAKEUCHI, H., 1995. The Knowl edge-Creating Company: How Japanese Companies Create the Dynamics of Innova tion. Oxford and New York: Oxford University Press.

ROBINSON, H. S., CARRILLO, P. M., ANUMBE, C. J. AND AL-GHASSANI, A. M., 2005, Knowledge management practices in large construction organizations, Engineering Con struction and Architectural Management, 12 (5), 431 - 446.

\section{ROYAL INSTITUTION OF CHARTERED SURVEY}

ORS, 1992. The Core Skills and Knowledge Base of the Quantity Survey or. London: Royal Institution of CharteredSurveyors, RICS Research Paper No. 19.

SZULANSKI, G., 1996. Exploring internal stickiness: impediments to the transfer of best practice within the firm. Strategic Management Jour nal, 17 (special issue), 27-43.

WILLIS, C.J., ASHWORTH, A., 1987, Practice and Procedure for the Quantity Surveyor, 9th ed, Collins, London.

WILLIS J. A., TRENCH W., (1999), Elements of Quantity Surveying Willis Paper back. Blackwell Science, London.

YIN, R. K., 1994. Case Study Research Design and Methods. 2nd ed. Sage. Thousand Oaks, CA.

ZOU, X. W., 2004. Knowledge management practice in two Australian Architecture - Engineer ing - Construction (AEC) Companies. The Australian Journal of Construction Econom ics and Buildings, 4 (2), $19-31$ 